\title{
Baseline chest radiographic findings among HIV positive adults in a poor resource economy
}

\author{
Faruk Kabir Umar', Sule Ahmed Saidu², Sadisu Ma'aji ${ }^{3}$, Muhammad Danfulani ${ }^{4}$, \\ Garba Haruna Yunusa ${ }^{5}$, Ibrahim Haruna Gele ${ }^{6}$, Akininibosun Raji Hafsat ${ }^{7}$, \\ Garba A Joshua ${ }^{8}$, Halimat Hassan Amin ${ }^{9}$, Yahaya Mohammed ${ }^{10}$ \\ ${ }^{1}$ Consultant Radiologist, ${ }^{2,3}$ Professor of Radiology and Consultant Radiologist, ${ }^{4,5}$ Associate Professor of Radiology and \\ Consultant Radiologist, ${ }^{6,7,8}$ Consultant Radiologist, Department of Radiology, Usmanu Danfodiyo University Teaching Hospital, \\ Sokoto. Nigeria, ${ }^{9}$ Senior Resident, Department of Internal Medicine, Usmanu Danfodiyo University Teaching Hospital, Sokoto. \\ Nigeria, ${ }^{10}$ Associate Professor of Clinical Microbiology and Consultant Clinical Microbiologist, Department of Clinical Medical \\ Microbiology, College of Health Sciences, Usmanu Danfodiyo University/Teaching Hospital, Sokoto. Nigeria
}

Background: Human Immunodeficiency Virus (HIV) infection has been known to pose one of the most formidable challenges to progress and development. It is a public health burden associated with high morbidity. Chest radiograph is an important tool in manifesting some of the findings associated with HIV. Aims and Objectives: To determine the baseline chest radiographic findings among HIV positive adults in a poor resource economy. Materials and Methods: 140 Newly diagnosed adult HIV positive, HAART naïve, participants were recruited in the Radiology Department of Usmanu Danfodiyo University Teaching Hospital (UDUTH) Sokoto and had their chest radiograph done using Silhoutte VR System GE diagnostic x-ray equipment. The processed radiographs were viewed using an illuminated viewing box and then reported by the investigator and cross-checked by another consultant Radiologist. Data collated was analysed using SPSS version 23. Results: The study showed female to male ratio of 2.2: 1 . Normal chest radiographic finding was found in $67(47.9 \%)$ participants. Pulmonary consolidation $32(22.9 \%)$ constituted the highest abnormal chest finding. The least of the abnormal radiographic findings were emphysematous bullae $1(0.7 \%)$ and plate atelectasis $1(0.7 \%)$. Majority of the lesions were in the upper zone, $43(30.7 \%)$ and on the right side. Conclusion: The study provides baseline data on the chest radiographic patterns among the HAART naïve HIV positive adult patients in a poor resource economy.

Keywords: Chest Radiographic findings; HIV; Adult
http://nepjol.info/index.php/AJMS DOI: 10.3126/ajms.v12i7.33177

E-ISSN: 2091-0576

P-ISSN: 2467-9100

Copyright (c) 2021 Asian Journal of Medical Sciences

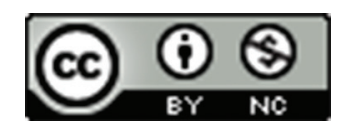

This work is licensed under a Creative Commons Attribution-NonCommercial 4.0 International License.

\section{INTRODUCTION}

Human Immunodeficiency Virus (HIV) infection and Acquired Immune Deficiency Syndrome (AIDS) form a spectrum of conditions caused by infection with the human immunodeficiency virus., ${ }^{1,2}$ The virus damages the immune system making the affected individual susceptible to opportunistic infections and malignancies which are common in the chest. ${ }^{3} \mathrm{It}$ is a global emergency that poses one of the most formidable challenges to progress, stability and development. ${ }^{4}$
It has been estimated that more than 25 million people have died from HIV worldwide. ${ }^{5,6}$ At least 33 million people are currently living with HIV, with about 2 million deaths from AIDS related diseases every year. ${ }^{3,-9}$ About 3.2 million of those living with HIV reside in Nigeria where the national standardized prevalence was estimated to be $3.2 \%$ in $2016 .{ }^{6}$

The Joint United Nations Program on HIV/AIDS (UNAIDS) documented a prevalence of $6.4 \%$ for HIV in Sokoto. ${ }^{10}$ In 2013 alone, Awolafa and Ogundele reported 
that 220,393 new HIV infections and 210,031 deaths were recorded in Nigeria. ${ }^{7}$ Therefore HIV/AIDS remains one of the major global public health problems because of its resultant high morbidity and mortality and has generated a lot of interest in the past three decades. ${ }^{3,5,11}$ In the severely affected nations, it has reduced the life expectancy of the population by more than 20 years, slowed down economic growth and deepened household poverty. ${ }^{11}$

Pulmonary infection was the dominant presentation in the first few years of the epidemic, and infectious and non-infectious lung diseases remain the leading causes of morbidity and mortality in persons living with HIV despite the development of effective antiretroviral therapy. ${ }^{15}$ In addition to the known infection risks, it is becoming increasingly recognized that HIV promotes the risks of non-infectious pulmonary and cardiovascular diseases through a number of different mechanisms, including direct tissue toxicity by HIV related viral proteins and the secondary effects of co-infections. ${ }^{14,15} \mathrm{HIV}$ diagnosis is mainly laboratory either by the detection of virus specific antibodies (anti-HIV) or by direct identification of the viral material but the recommended first line assay is one which tests for HIV antibody and p24 antigen simultaneously. ${ }^{6}$

Chest radiography is an important tool in assessing the pulmonary complications as well as manifestations of HIV/AIDS. ${ }^{4,16}$ Its sensitivity and specificity in detecting pulmonary complications in patients with HIV was noted to be $98 \%$ and $93 \%$ respectively. ${ }^{3}$ It is readily available, affordable and more importantly delivers less radiation dose to patients when compared to imaging modalities like computed tomography (CT) and they can be reproduced in most hospitals of developing countries. ${ }^{12}$ Unlike CT, superimposition of surrounding structures because of its two-dimensional representation, stands as the major drawback of chest radiography.

Several studies have documented the spectrum and pattern of chest radiographic findings in patients with HIV. The common chest findings documented include but not limited to pulmonary nodules, interstitial pulmonary infiltrates, reticulonodular shadows, bronchial wall thickening, consolidation, cavitation, plate atelectasis, lung collapse, enlarged lymph nodes, bullae, pneumothorax, pleural effusion and normal findings. ${ }^{3-5,15}$

This baseline chest radiographic findings among HIV positive patients in a poor resource economy will be of help to the clinicians for possible recognition of various chest radiographic findings seen in HIV patients. It may also add to the knowledge and experience of the physicians and radiologists in predicting the degree of immunosuppression from chest radiographic findings and vice versa.

\section{MATERIALS AND METHODS}

Newly diagnosed HIV positive patients were recruited in the Radiology Department at the point of conducting the routine chest radiographic examination requested by the attending physician. The reason, benefit, method and implication of the research were explained to the patient after which he/she signed a written informed consent. Approval was obtained from the Institutional Ethics Committee prior to the commencement of the study. The patient was then interviewed and a structured questionnaire containing information on patient's age, gender, ethnicity, occupational status, religion and anthropometric measurements (weight and height) was correctly filled. The Body Mass Index (BMI) was also documented.

The recruited patients were then sent to the radiographic examination room after brief explanation of the procedure.

The examination was performed in the radiography room using Silhoutte VR System GE diagnostic x-ray equipment (Model No: 2226680), manufactured in July 2007 at Japan.

The radiographs were viewed using an illuminated viewing box and then reported by the investigators and cross-checked by another Radiologist in the department. The presence of consolidation, interstitial pulmonary infiltrates, reticulonodular opacities, plate atelectasis, fibrosis, cavitation, cardiomegaly, enlarged lymph nodes, lung collapse, pleural effusion, and bullae with their distribution were documented in the questionnaire. Normal radiographs were also documented.

Data collated (socio-demographic, laboratory and radiographic) was entered into a computer, checked for accuracy and then subsequently analysed using the Statistical Package for Social Sciences (SPSS) IBM version 23.

Data analysis comprised of descriptive statistics using mean and standard deviation (SD) for normally distributed quantitative data and frequency and percentages for qualitative data. This was followed by bivariate analysis to show the association between the pattern of radiographic chest findings using Chi-square test with the level of statistical significance set at 5\% $(p<0.05)$. Multivariate analysis using logistic regression and odds ratio/confidence interval was used to determine the predictor of abnormal chest radiographic findings. The result was presented in form of tables, graphs and figures as appropriate.

\section{RESULTS}

A total of 140 newly diagnosed HAART naïve HIV positive patients were recruited during the study period. 
They constituted $96(68.6 \%)$ females and $44(31.4 \%)$ males with female to male ratio of 2.2:1. Their age ranges between 17-60 years with the mean of $37.1 \pm 10.4$ years. The highest proportion of the study participants, $43(30.7 \%)$ belonged to the 31-40 years age group, followed closely by the $41-50$ years age group with $41(29.3 \%)$, while the least number of patients $8(5.7 \%)$ were found in the 11- 20 years age group. Hausas constituted the majority ethnic group among the studied participants with $98(70 \%)$ respondents, followed by 12(8.6\%) Igbos and 12(8.6\%) Yorubas. One hundred and two $(72.9 \%)$ of the patients were Muslims and 38(27.1\%) were Christians. Most of them were unemployed- $72(51.4 \%)$, while $39(27.9 \%)$ were Civil Servants and 29(20.7\%) were self-employed. The body mass index (BMI) of the studied group was between 12.12 to 38.72 with a mean of $23.16 \pm 5.48$. Half of the participants $70(50 \%)$ were of normal weight $(\mathrm{BMI}=18.5-24.9)$ with $26(18.6 \%)$ and $25(17.8 \%)$ in the underweight $(\mathrm{BMI}=<18.5)$ and overweight $(\mathrm{BMI}=$ 25.0- 29.9) categories respectively. Only $19(23.6 \%)$ of the patients were obese (BMI $\geq 30.0)$. These details are as shown in Table 1.

\section{Chest radiographic findings among the participants}

Normal chest radiographic findings were found in $67(47.9 \%)$ patients, while the remaining $73(52.1 \%)$ were abnormal. Of the participants that had abnormal findings, $32(22.9 \%)$ had pulmonary consolidation, $22(15.7 \% \%)$ had diffuse (alveolar and interstitial) pulmonary infiltrates followed by $15(3.9 \%)$ participants with cavity and $8(5.7 \%)$ with reticulo-nodular opacities. Hilar lymphadenopathy was demonstrated in $8(5.7 \%)$ participants, cardiomegaly in $6(4.3 \%)$ patients, pleural effusion in $5(3.6 \%)$ participants and fibrosis in $3(2.1 \%)$ participants. Other findings were lung collapse in $2(1.4 \%)$ participants, emphysematous bullae in $1(0.7 \%)$ and plate atelectasis in $1(0.7 \%)$ participant. The details are as shown in Table 2.

The highest number of lesions were in the upper zone, $43(30.7 \%)$. The remaining locations had the following distributions; middle zone lesions 31(22.1\%) and lower zone lesions 24(17.1\%). Bilateral lesions were $21(15 \%)$, while $30(21.4 \%)$ and $20(14.3 \%)$ lesions were present on the right and left sides respectively. This is as shown in Table 3.

Figures 1-4 show radiographs depicting some of the chest radiographic findings noted among the participants.

\section{DISCUSSION}

Human Immunodeficiency Virus (HIV) infection frequently presents with a wide spectrum of pulmonary, pleural and cardiac manifestations that may be associated

\begin{tabular}{|c|c|c|}
\hline Variables & Frequency $(n=140)$ & Percentage \\
\hline \multicolumn{3}{|l|}{ Gender } \\
\hline Male & 44 & 31.4 \\
\hline Female & 96 & 68.6 \\
\hline \multicolumn{3}{|l|}{ Age group (years) } \\
\hline $11-20$ & 8 & 5.7 \\
\hline $21-30$ & 33 & 23.6 \\
\hline $31-40$ & 43 & 30.7 \\
\hline $41-50$ & 41 & 29.3 \\
\hline $51-60$ & 15 & 10.7 \\
\hline \multicolumn{3}{|l|}{ Tribe } \\
\hline Hausa & 98 & 70.0 \\
\hline Igbo & 12 & 8.6 \\
\hline Yoruba & 12 & 8.6 \\
\hline Others & 18 & 12.8 \\
\hline \multicolumn{3}{|l|}{ Religion } \\
\hline Islam & 102 & 72.9 \\
\hline Christianity & 38 & 27.1 \\
\hline \multicolumn{3}{|l|}{ Occupation } \\
\hline Civil Servants & 39 & 27.9 \\
\hline Self employed & 29 & 20.7 \\
\hline Unemployed & 72 & 51.4 \\
\hline \multicolumn{3}{|l|}{ Body Mass Index (BMI) } \\
\hline$<18.5$ (Underweight) & 26 & 18.6 \\
\hline 18.5-24.9 (Normal) & 70 & 50.0 \\
\hline 25.0-29.9 (Overweight) & 25 & 17.8 \\
\hline$\geq 30$ (Obese) & 19 & 13.6 \\
\hline
\end{tabular}

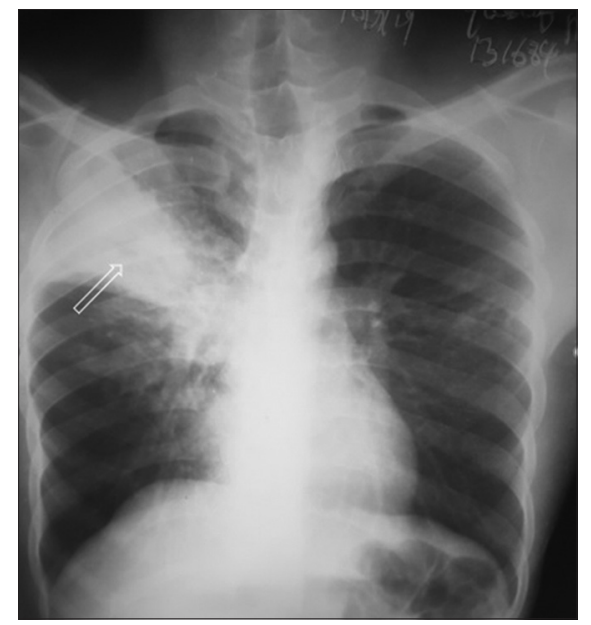

Figure 1: Frontal chest radiograph of a 42-year-old male patient with CD4 count of 355 cells/ $/ \mathrm{L}$ showing an inhomogeneous opacity with positive air-bronchogram sign in the right upper lung zone limited inferiorly by the horizontal fissure in keeping with upper lobe consolidation (straight arrow)

with high mortality rates. ${ }^{17}$ These conditions often manifest radiographically, though with some degree of overlap, variability and non-specificity. 2,5

The study showed female preponderance with female to male ratio of 2.2:1. This is similar to the findings of Ibinaiye et $\mathrm{al}^{12}$, Akinola et $\mathrm{al}^{3}$ and Akinbami et $\mathrm{al}^{16}$ in MaiduguriNorth Eastern Nigeria and Lagos- South Western Nigeria 


\begin{tabular}{|c|c|c|}
\hline \multirow[t]{2}{*}{${ }^{* *}$ Chest findings } & \multicolumn{2}{|c|}{ Frequency $(\mathrm{N}=140)$} \\
\hline & Right & Left \\
\hline \multicolumn{3}{|l|}{ Consolidation $(n=32)$} \\
\hline upper zone & $11(7.9 \%)$ & $7(5.0 \%)$ \\
\hline middle zone & $4(2.9 \%)$ & $2(1.4 \%)$ \\
\hline lower zone & $7(5.0 \%)$ & $4(2.9 \%)$ \\
\hline \multicolumn{3}{|l|}{ Pulmonary infiltrates $(n=22)$} \\
\hline upper zone & $9(6.4 \%)$ & $7(5.0 \%)$ \\
\hline middle zone & $7(5.0 \%)$ & $3(2.1 \%)$ \\
\hline lower zone & $3(2.1 \%)$ & $1(0.7 \%)$ \\
\hline \multicolumn{3}{|l|}{ Cavity $(n=10)$} \\
\hline upper zone & $2(1.4 \%)$ & $2(1.4 \%)$ \\
\hline middle zone & $2(1.4 \%)$ & $3(2.1 \%)$ \\
\hline lower zone & $0(0.0 \%)$ & $1(0.7 \%)$ \\
\hline \multicolumn{3}{|l|}{ Reticulonodular opacity $(n=8)$} \\
\hline upper zone & $3(2.1 \%)$ & $4(2.9 \%)$ \\
\hline middle zone & $6(4.3 \%)$ & $7(5.0 \%)$ \\
\hline lower zone & $5(3.6 \%)$ & $5(3.6 \%)$ \\
\hline \multicolumn{3}{|l|}{ Plate atelectasis $(n=1)$} \\
\hline upper zone & $0(0.0 \%)$ & $0(0.0 \%)$ \\
\hline middle zone & $1(0.7 \%)$ & $0(0.0 \%)$ \\
\hline lower zone & $0(0.0 \%)$ & $0(0.0 \%)$ \\
\hline \multicolumn{3}{|l|}{ Lung collapse $(n=2)$} \\
\hline upper zone & $1(0.7 \%)$ & $1(0.7 \%)$ \\
\hline middle zone & $0(0.0 \%)$ & $1(0.7 \%)$ \\
\hline lower zone & $0(0.0 \%)$ & $1(0.7 \%)$ \\
\hline \multicolumn{3}{|l|}{ Emphysematous bullae $(n=1)$} \\
\hline upper zone & $1(0.7 \%)$ & $0(0.0 \%)$ \\
\hline middle zone & $0(0.0 \%)$ & $0(0.0 \%)$ \\
\hline lower zone & $0(0.0 \%)$ & $0(0.0 \%)$ \\
\hline Hilar lymphadenopathy $(n=8)$ & $6(4.3 \%)$ & $2(1.4 \%)$ \\
\hline Pleural effusion $(n=5)$ & $2(1.4 \%)$ & $3(2.1 \%)$ \\
\hline Lung fibrosis $(n=3)$ & $2(1.4 \%)$ & $1(0.7 \%)$ \\
\hline${ }^{*}$ Cardiomegaly $(n=6)$ & \multicolumn{2}{|c|}{$6(4.3 \%)$} \\
\hline *Normal chest $(n=67)$ & \multicolumn{2}{|c|}{$67(47.9 \%)$} \\
\hline
\end{tabular}

** Some participants had a combination of these findings *No right and left classification

\begin{tabular}{lcc}
\multicolumn{3}{l}{ Table 3: Anatomic location of Lesions } \\
\hline **Location & Frequency & Percentage \\
\hline Upper zone & 43 & 30.7 \\
Middle zone & 31 & 22.1 \\
Lower zone & 24 & 17.1 \\
Right side & 30 & 21.4 \\
Left side & 20 & 14.3 \\
Bilateral & 21 & 15.0 \\
\hline
\end{tabular}

** Some participants had a combination of these findings.

respectively. The higher vulnerability of females could be due to their biological make-up and socio- cultural factors such as polygamy and non-compliance with pre-marital HIV screening as a routine practice. ${ }^{12}$ Female freedom to marry and re-marry when divorced could also be a contributing factor in this environment. It is however noteworthy that Oguntoyibo et $\mathrm{al}^{4}$, Desalu et $\mathrm{al}^{14}$, Ahidjo et $\mathrm{al}^{18}$ and Kitara et $\mathrm{al}^{11}$ reported male preponderance in their studies in Ilorin, North-Central Nigeria, Yola- North Eastern Nigeria, Maiduguri- North Eastern Nigeria and Uganda respectively. This variation could be due to the

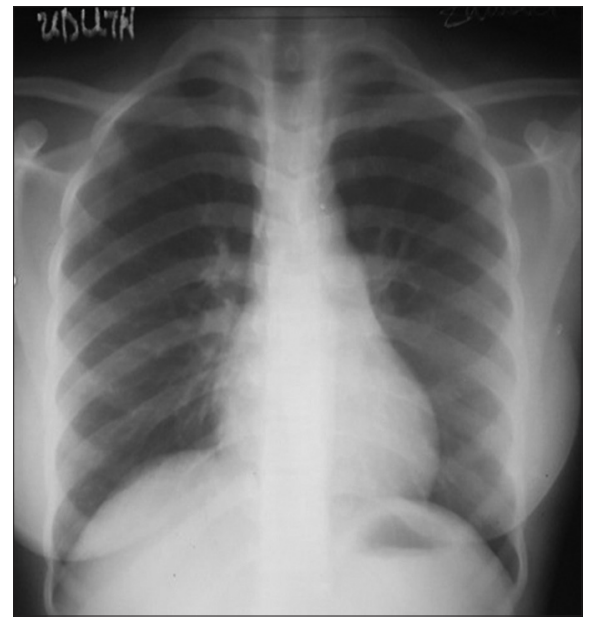

Figure 2: Frontal chest radiograph of a 31-year-old female participant with CD4 count of 1080 cells $/ \mu \mathrm{L}$ showing normal cardiac, pulmonary and pleural shadows in keeping with a normal study

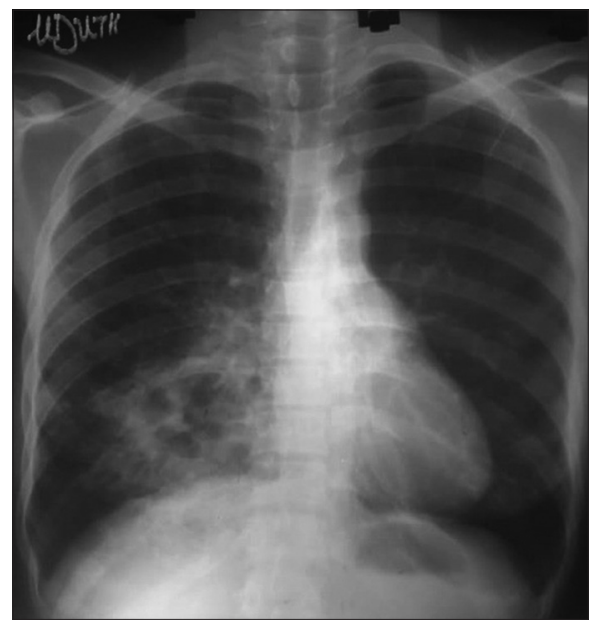

Figure 3: Frontal chest radiograph of a 38-year-old male patient with CD4 count of 406 cells/ $\mu \mathrm{L}$ showing a thick-walled cavity in the right lower lung zone. Areas of inhomogeneous opacity are also demonstrated superomedial and inferolateral to the cavity, suggestive of consolidation

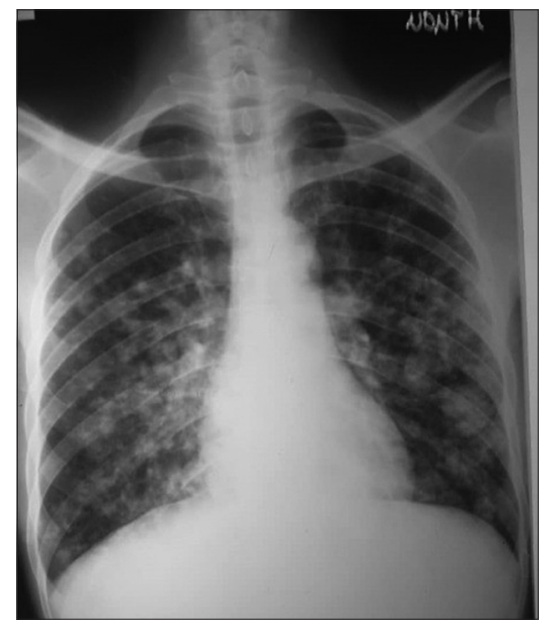

Figure 4: Frontal chest radiograph of a 29-year-old male patient with CD4 count of 282 cells $/ \mu \mathrm{L}$ showing widespread reticulonodular opacities with coalescence in the left middle zone 
restriction of their studies to only HIV patients with pulmonary tuberculosis (PTB) co-infection.

Abnormal chest radiographic findings were recorded in more than half of our study participants. This is in agreement with the findings of Atalabi et $\mathrm{al}^{5}$ and Adeyekun et $\mathrm{al}^{19}$ in Ibadan- South Western Nigeria and Benin city South-South Nigeria respectively. In contrast, Akinola et $\mathrm{al}^{3}$, Akinbami et $\mathrm{al}^{16}$ and Ahidjo et $\mathrm{al}^{18}$ from Lagos and Maiduguri respectively reported abnormal chest radiographic findings in less than half of their studied participants. The contrast could be due to the sample size variation between the two groups.

Majority of the lesions found in this study were in the upper zones and on the right side. This is similar to the findings reported by Atalabi et $\mathrm{al}^{5}$ in a study conducted in Ibadan to show the baseline chest radiographic features among antiretroviral therapy naïve human immuno-deficiency virus positive children in a pediatric care program.

Chest radiograph being one of the tools to assess the cardiopulmonary and pleural complications has limitations of presenting overlapping appearances. However, certain basic radiographic patterns can be recognised which should raise suspicion of certain underlying diseases. ${ }^{20}$ Recognition of these dominant radiographic patterns in the HIV/ AIDS patients is key to establishing an accurate and helpful differential diagnosis.

Knowledge of how CD4 lymphocyte count is correlated with the radiographic appearance can further limit the differential diagnoses in a patient with HIV infection because certain infections and neoplasms are uncommon above a specific CD4 lymphocyte count. ${ }^{21}$ This study showed pulmonary consolidation, pulmonary infiltrates, cavity, reticulonodular opacities, plate atelectasis, lung collapse, emphysematous bullae, hilar/mediastinal lymphadenopathy, pleural effusion, lung fibrosis and cardiomegaly as the baseline chest radiographic findings. The most dominant among them were pulmonary consolidation, pulmonary infiltrates, cavity and reticulonodular opacities with prevalence of $22.9 \%$, $15.7 \%, 7.1 \%$, and $5.7 \%$ respectively. This is comparable with the findings reported by Akinola $\mathrm{et} \mathrm{al}^{3}$ and Akinbami et al. ${ }^{16}$ The concordance in these studies may be due to the similarity in the average immune status of the study groups as all the three groups were HAART-naïve HIV/ AIDS patients presenting to the hospital for the first time and that can also be linked to a common geographical location.

Emphysematous bullae being also a prominent feature of PCP, was found in only one patient among those in the current study and falls within the aforementioned CD4 group. This is similar to the findings of Akinola et al. ${ }^{3}$

This study showed typical radiographic features of PTB (reticulo-nodular opacities, cavities, lung collapse, lung fibrosis, and pleural effusion) in $19.9 \%$ of the patients. This finding is close to the $22.5 \%$ reported by Singh et a ${ }^{22}$ in India. It is however markedly less than the findings by Adeyekun et $\mathrm{al}^{23}$ in Benin city, Nigeria and greater than the findings from Lagos, Nigeria, ${ }^{3,17}$. The difference could be due to small and large sample sizes used by the Benin and Lagos authors respectively, compared to this study.

\section{CONCLUSION}

This study provides baseline data on the prevalence of chest radiographic patterns among the HAART naïve HIV positive adult patients in Sokoto, North western Nigeria.

\section{REFERENCES}

1. Sepkowitz KA. AIDS-the first 20 years. N Engl J Med. 2001; 344:1764-1772.

https://doi.org/10.1056/NEJM200106073442306

2. Rajeev S, Pandya HP and Chaturvedi P. Spectrum of various fungal \& bacterial respiratory tract opportunistic infections in relation to mean CD4 count profile among HIV patients of Gujarat, India. Int J Curr Microbiol App Sci. 2014; 3:64-72.

3. Akinola RA, Balogun TM, Adeniyi AA, Onakoya JA and Fabeyibi IO. Spectrum of Chest X-Ray Findings among Human Immunodeficiency Virus Positive Individuals in a Nigerian Tertiary Hospital. SAARC J TUBER LUNG DIS HIVIAIDS. 2014; 10:27-34.

https://doi.org/10.3126/saarctb.v10i2.9710

4. Oguntoyinbo AE, Nzeh DA, Salami AK and Babatunde AS. The chest radiographs of suspected and confirmed HIV/AIDS patients-pattern of radiological features in Ilorin. Trop J Health Sci. 2008; 15:71-77.

https://doi.org/10.4314/tjhc.v15i1.36760

5. Atalabi OM, Oladokun R, Adedokun B, Obajimi MO and Osinusi K. Baseline chest radiographic features among antiretroviral therapy naïve human immuno-deficiency virus positive children in a pediatric care program. W Afr J Radiol. 2012; 19:5-13.

6. Kumar $P$ and Clark M. Infectious diseases tropical medicine and sexually transmitted infections. In: Kumar and Clark's clinical medicine, $8^{\text {th }}$ Ed. London. Elsevier limited; 2012: 171-194.

7. Awofala AA and Ogundele OE. HIV epidemiology in Nigeria. Saudi J Biol Sci. 2016; 79: 68-72.

8. Global AIDS Report. Available from; http://www.unaids.org/sites/ default/files/media_ asset/global_ AIDS_update_2016_en.pdf. Assessed on 19/03/2017.

9. Rotheram-Borus MJ, Swendeman D and Chovnick G. The past, present, and future of HIV prevention: integrating behavioral, biomedical, and structural intervention strategies for the next generation of HIV prevention. Annu Rev Clin Psycho. 2009; 5: 143-167.

10. NGA Narrative report 2014. Available from http://www.unaids. org/sites/default/files/country/documents/NGA_narrative_ 
report 2014.pdf. Assessed on 19/03/2017.

11. Kitara DL, Pirio P, Acullu D and Opira CP. TB co-infection with HIVIAIDS: a unique radiological presentation at Lacor hospital-a post conflict northern Uganda. Afri J Infect Dis. 2015; 9:21-28. https://doi.org/10.4314/ajid.v9i2.1

12. Ibinaiye PO, Tahir NM, Saad ST, TahirA, Ahidjo A, Yusuf H, et al. Relationship between the radiographic pattern of pulmonary tuberculosis and CD4 cell count in patients with human immune deficiency virus infection. Archives of International Surgery. 2014; 4:85-89.

https://doi.org/10.4103/2278-9596.143084

13. Kumar V, Abbas AK, Fausto $\mathrm{N}$ and Aster JC. Diseases of Immunity. In: Robbins and Cotran pathologic basis of disease. $7^{\text {th }}$ ed. Philadelphia. Elsevier Health Sciences; 2014:245-258.

14. Desalu OO, Danfulani M, Gambo Z, Salawu F, Damburam A and Midala J. Impact of immunosuppression on radiographic features of HIV related pulmonary tuberculosis among Nigerians. Turk Thorac J. 2009; 1:112-117.

15. Staitieh B and Guidot DM. Noninfectious pulmonary complications of human immunodeficiency virus infection. Am J Med Sci. 2014; 348:502-511.

https://doi.org/10.1097/MAJ.0000000000000318

16. Akinbami AA, Adegboyega AO, Oshinaike OO, Adebola PA, Enabulele C, Dosunmu OA, et al. Chest X-ray findings in HIV patients in relation to the CD4 count. Nig Q J Hosp Med. 2010; 21:306-311.

17. Akinbami A, Balogun B, Balogun M, Dosunmu O, Oshinaike O,
Adediran A, et al. Chest X-ray findings in HIV-infected Highly Active Antiretroviral Treatment (HAART)-naïve patients. Pan Afr Med J. 2013; 12.

18. Ahidjo A, Yusuph $\mathrm{H}$ and Tahir A. Radiographic features of pulmonary tuberculosis among HIV patients in Maiduguri, Nigeria. Ann Afr Med. 2005; 4:7-9.

19. Adeyekun $A A$ and Onunu $A N$. Chest radiographic findings in Human Immunodeficiency Virus disease in Benin City, Nigeria. Annals of Biomedical Sciences. 2002; 1:131-135. https://doi.org/10.4314/abs.v1i2.40633

20. Allen $\mathrm{CM}, \mathrm{AL}$-Jahdali $\mathrm{HH}$, Irion $\mathrm{KL}, \mathrm{Al}$ Ghanem $\mathrm{S}$, Gouda $\mathrm{A}$ and Khan AN. Imaging lung manifestations of HIVIAIDS. Ann Thorac Med. 2010; 5:201. https://doi.org/10.4103/1817-1737.69106

21. Padyana $M$, Bhat $R V$, Dinesha $M$ and Nawaz $A$. HIVtuberculosis: A study of chest X-Ray patterns in relation to CD4 count. North Am J Med Sci. 2012; 4:221-225. https://doi.org/10.4103/1947-2714.95904

22. Singh RP, Kashyap AK, Puri S, Whig J. Pulmonary manifestations in HIV seropositive patients and their correlation with CD4 counts in a tertiary care Centre of North India. J K Science. 2013; 15:140-144.

23. Opara DC, Umoh BI and John M. Socio-demographic and anthropometric variables of persons living with HIV and AIDS in Uyo, South Eastern Nigeria. Pak J Nutr. 2007; 6:547-557. https://doi.org/10.3923/pjn.2007.547.557

\section{Author's Contribution:}

FKU - Concept and design of the study, literature review, designing methodology, statistical analysis and interpretation of result, prepared draft of the discussion SAS - Reviewed the concept and study design, reviewed the methodology, final result interpretation and the final manuscript; SMM, MD, GHY - Reviewed the statistical analysis, designed the framework for result discussion; IHG, OARH, KGJ - Image re-interpretation and documentation; HHA - Data analysis and discussion; YM - Patient recruitment, referral and CD4 investigation.

\section{Work Attributed to:}

Usmanu Danfodiyo University/Teaching Hospital Sokoto

\section{Orcid ID:}

Dr. Faruk Kabir Umar - (10 https://orcid.org/0000-0002-2080-0123

Prof. Sule Ahmed Saidu - (1) https://orcid.org/0000-0003-2414-4888

Prof. Sadisu Ma'aji - (1) https://orcid.org/0000-0002-7142-9387

Dr. Muhammad Danfulani - (D) https://orcid.org/0000-0001-8698-5944

Dr. Garba Haruna Yunusa - (i) https://orcid.org/0000-0003-3885-7432

Dr. Ibrahim Haruna Gele - (1) https://orcid.org/0000-0002-4009-6612

Dr. Akininibosun Raji Hafsat - (1) https://orcid.org/0000-0002-7234-4570

Dr. Garba A Joshua - (D) https://orcid.org/0000-0002-6287-1966

Dr. Halimat Hassan Amin - (1) https://orcid.org/0000-0002-1776-0861

Dr. Yahaya Mohammed - (i) https://orcid.org/0000-0003-0075-9511

Source of Funding: UDUTH Residency training fund, Conflict of Interest: None 